\title{
Social Media Sad Girls and the Normalization of Sad States of Being
}

\author{
Fredrika Thelandersson \\ RUTGERS UNIVERSITY, MEDIA STUDIES
}

This paper examines virtual manifestations of "sad girls" on the media platform Tumblr. Here users write about their struggles with mental illness, revealing a set of shared experiences that encompass both psyche and body. Predominant narratives of what it means to be mentally ill are questioned, and alternative conceptualizations of the psyche are introduced. I argue that the sad girls legitimize each other's experiences of mental illness while also romanticizing melancholic sadness. I use the concept of sadness as referring to a multifaceted affect that includes clinical diagnoses like depression as well as general sad sentiments. By looking at the way content is circulated in a meme-tic fashion among the sad girls on Tumblr, I discuss how a shared discourse around sadness is created. I suggest that this collective discourse is an example of what Lisa Blackman calls "distributed forms of perception," which can be seen "in social media practices that allow traces and fragments to become linked together to assume a collective authorial voice" (2015, p. 37). I ask if the sad girl represents a new kind of sadness that challenge the norms around mental illness which tend to conceive it as something to be immediately cured. This question is examined by mapping out various ways of conceptualizing and analyzing sadness. Finally, I discuss the productive possibilities of resting in sadness by examining the sad girls' potential resistance to neoliberal demands for self-governance.

\section{KEYWORDS}

sad girls, Tumblr, affect, depression, social media 


\section{Introduction}

This paper examines virtual manifestations of "sad girls" on the media platform Tumblr. On this multimodal blogging platform users write about their struggles with mental illness, revealing a set of shared experiences that encompass both psyche and body. Predominant narratives of what it means to be mentally ill are questioned, and alternative conceptualizations of the psyche are introduced. In what follows, I introduce social media sad girls and discuss how they circulate content on Tumblr, including the relation between mediated process and the configuration of the sad girl herself. I ask if the sad girl represents a new kind of sadness, exploring the question by mapping out various ways of conceptualizing and analyzing sadness. Finally, I discuss the productive possibilities of resting in sadness by examining the sad girls' potential resistance to neoliberal demands for self-governance and social performativity of happiness and success. I am also interested in why the figure of the sad girl has emerged at this moment in time. Do social media ecologies contribute to a new form of sadness, conceptualized and lived in ways shaped by the media through which it travels? And do the sad girls on Tumblr and Instagram represent a sadness that challenges traditional notions of mental health?

I use the concept of sadness as encompassing a multifaceted affect that includes clinical diagnoses like depression as well as general sad sentiments. In this I am influenced by Ann Cvetkovich's broad definition of affect in her study of depression. She writes that she uses affect "as a category that encompasses affect, emotion, and feeling, and that includes impulses, desires, and feelings that get historically constructed in a range of ways" (2012, p. 4). A broad definition of sadness (as encompassing mental illness diagnoses, melancholia, and a general sense of hopelessness and inertia), allows me to look at the connections between what is "officially" considered a mental health problem and what is considered common or insignificant sadness, and then examine how they overlap and interact with each other.

By virtue of being specifically sad girls, not guys, the sad girl raises questions about the gendered nature of the sadness and mental illness represented. The link between women and madness in Western culture has been strong since the late eighteenth century. The figure of the "madwoman" and the assumptions that accompany it have manifested themselves in medical as well as popular culture. 
Appearing under different names-neurasthenia, hysteria, schizophrenia, depression-mental instability has been culturally female, regardless of the actual statistics of genders represented in the clinical treatments of these ailments (Showalter 1985). I believe that the sad girl relates to the traditional "madwoman," in that she follows in the tradition of categorizing mental illness, or madness, as female. But she also differs in that social media users voluntarily adopt and self-identify as sad girls, and thus presents a subject position that diverges significantly from, for example, the $19^{\text {th }}$ century hysteric. In this essay, which is part of a larger dissertation project that examines the changing faces of female madness, I chose to put aside specific questions of gender and instead focus on mediated processes of subjectivation and the sad girls' relation to traditional models of mental health.

\section{Social media sad girls}

The sad girl can be found on multiple platforms and in various configurations. On social media, she is most present on Tumblr and Instagram. Some typical examples of content circulated by sad girls are pictures of pills in bright pink colors; animated texts that read things like "having a threesome with anxiety and depression;" glittering words that spell out "100\% Sad" (see Figure 1); and cartoon character Lisa Simpson lying face down on her bed with the word sad girl spelled out in the front and center of the image (Grvnge-nicotine 2015; Less-love-more-alcohol (n.d.); Animatedtextgifs 2016; Hollywood-noir 2015a).

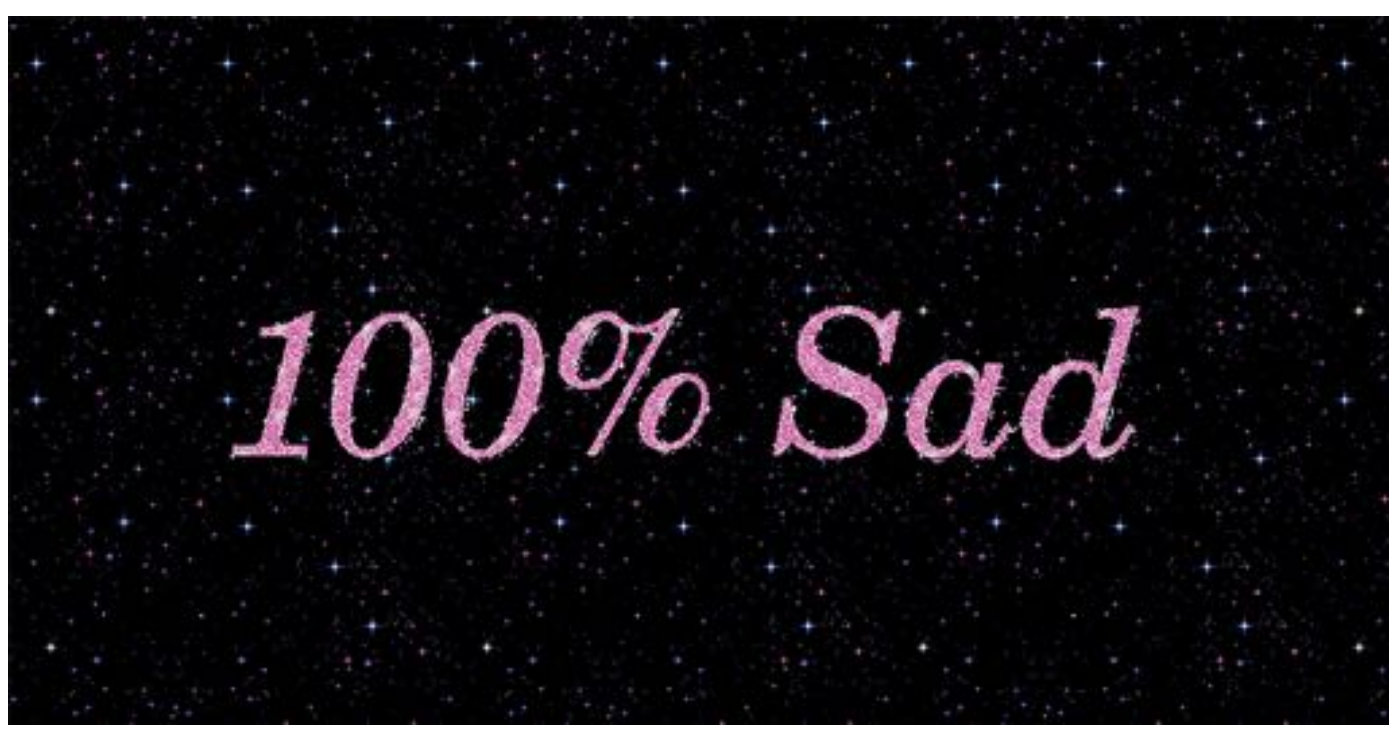

Figure 1: Less-love-more-alcohol (n.d.) 
Posts like these position sadness and depression as a shared and common experience. Statements like "having a threesome with anxiety and depression" does not portray anxiety and depression as by default negative ailments to be cured; neither does it position them as something to be ashamed of. Instead it states loud and clear that the person posting it is living with anxiety and depression, and has come to terms with it enough to formulate the suffering in a sarcastic way. One post about psychotropic drugs depicts pink pills in a polaroid-like frame with the word "Medicated" written at the bottom (see Figure 2).

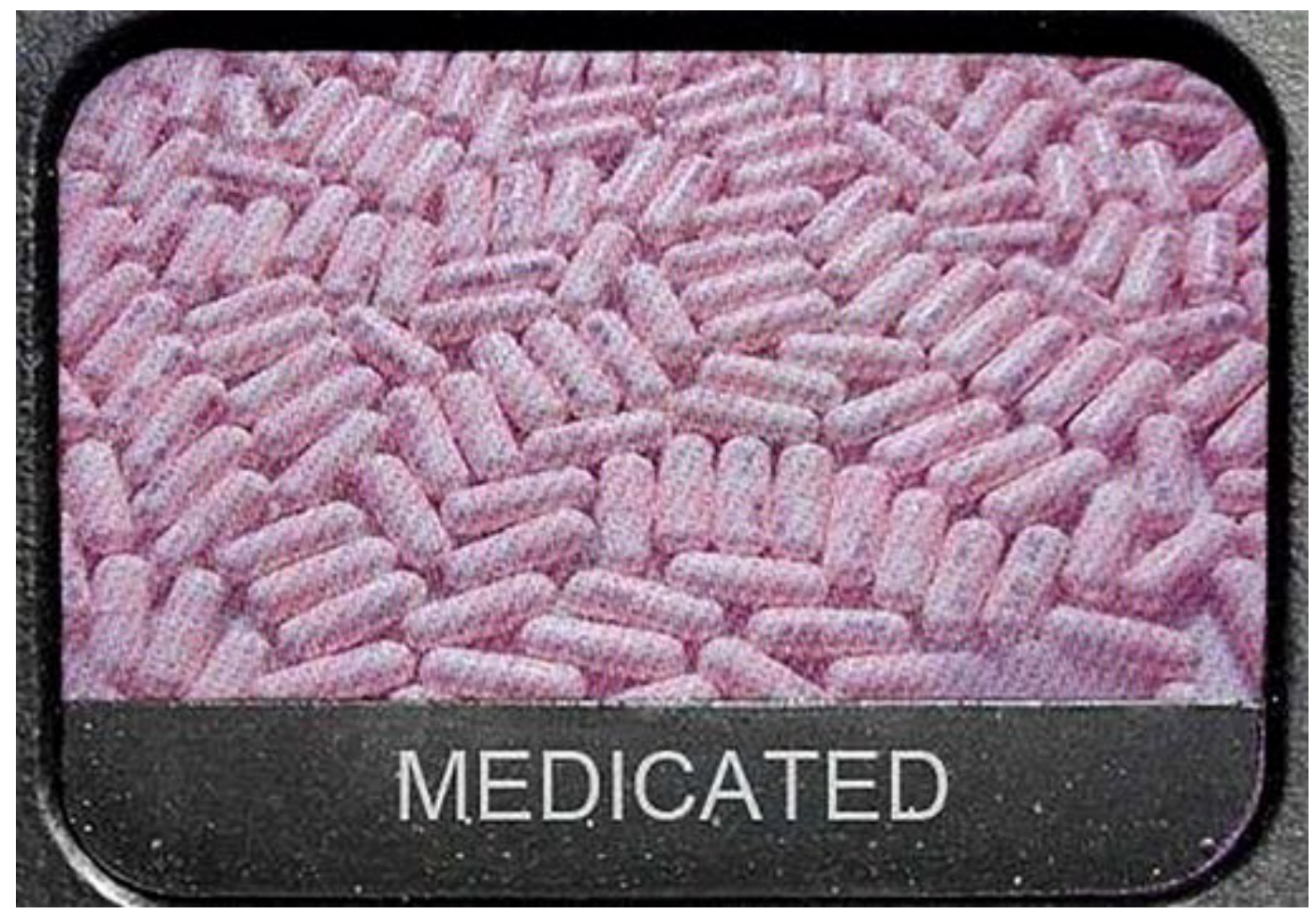

Figure 2: Grvnge-nicotine, 2015

Another is just a picture of a pile of turquoise pills with the imprint "S 90 3" (Havic-dp, 2014). A simple google search for this code reveals that the drug portrayed is the benzodiazepine Xanax. Posts like these both normalize and glorify psychopharmacology. There are also those that communicate the commonness of therapy, like a photograph of a framed poster that spells out "I told my therapist about you" (see Figure 3). 


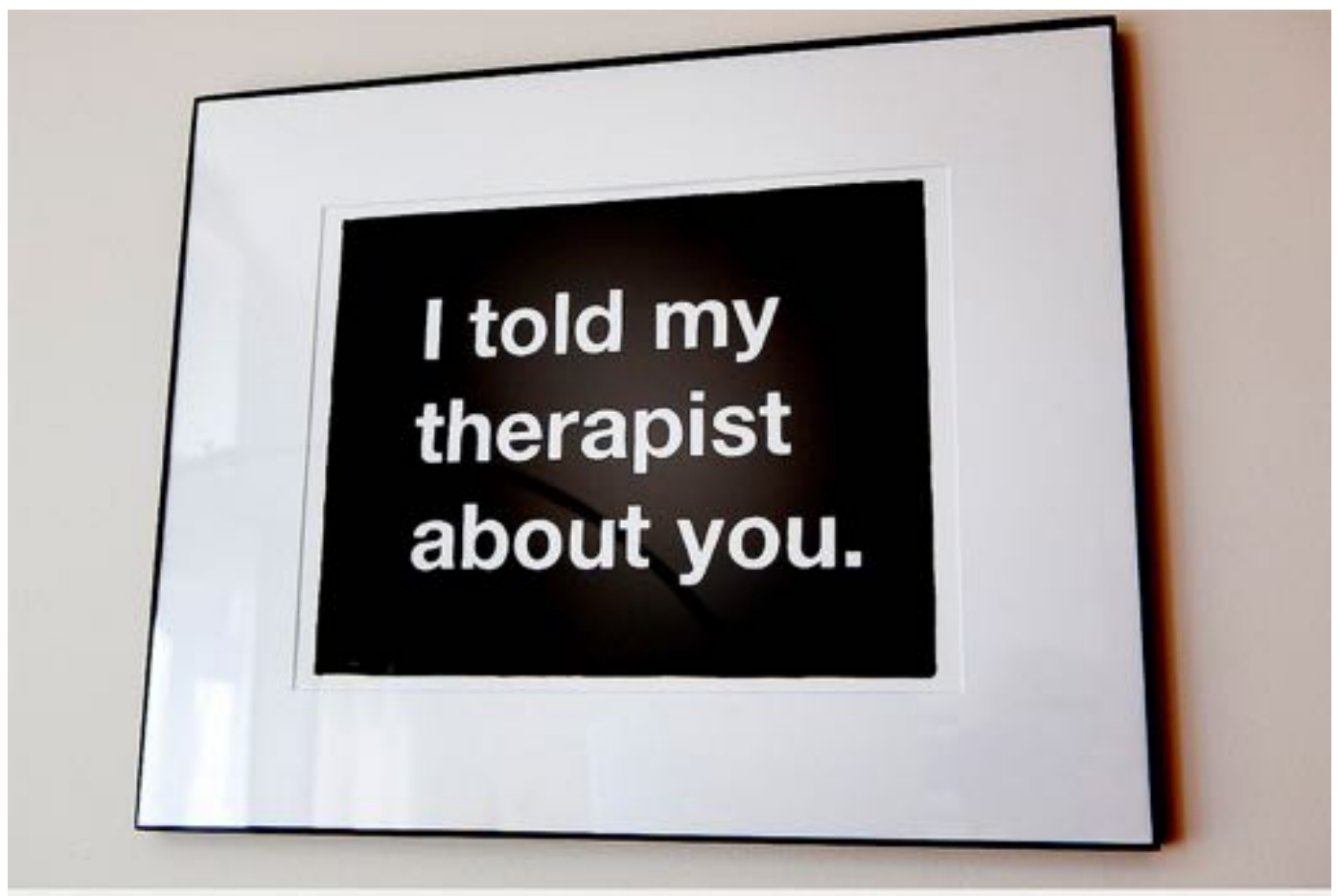

708,786 notes Posted on: Sunday 7 August 2016 Reblogged from tearjerkerr

Posted by dearscience-blog

Figure 3: Sweet-despondency, 2016

Among the sad girls on Tumblr, sadness and depression become normal rather than abnormal, to be sad and mad is something to strive for, it even becomes cool.

At the same time, mental illness has become increasingly visible in popular and celebrity culture. Several TV shows portray both diagnosed and undiagnosed mental illness in a non-stigmatized way (see, for example, Homeland (2011-); You're the Worst (2014-);Crazy Ex-Girlfriend (2015-); Kliegman 2015). In addition, more and more celebrities are coming out and talking about their own experiences of mental illness, frequently speaking out for awareness campaigns (Pugachevsky 2014; Shah 2016). The narrative told by celebrities tend to focus both on a road to recovery and the importance of "coming out" as a sufferer. Pop star and former Disney child actor Selena Gomez, is one example of the outspoken celebrity. In August 2016, she revealed that she was suffering from anxiety and depression. She has since talked repeatedly about the importance of getting help, and named the various strategies she has used. These include rehab, 
group therapy, dialectical behavior therapy, exercise, and self-care (Vogue.com 2017; McCall 2017). In similar fashion, pop star Miley Cyrus has said, in relation to her struggle with depression, that "every person can benefit from talking to somebody," and that despite her usual anti-medication views she has conceded that sometime medication is necessary (Gevinson 2014). Declarations like these work to remove the stigma associated with mental illness, and do so largely by classifying it as an ordinary sickness that can be cured.

The presence of sadness related content is also prevalent in online editions of women's magazines. A headline on MarieClaire.com reads "Depression Makes Looking Hot a Lot Harder" (May 12 2017). In the article, writer Annakeara Stinson describes the troubles she has had with getting motivated to dress well when in the thick of depression, and finally concludes that it is O.K. to only get to "adequately kempt" style-wise most days. Stating that "Depression Makes Looking Hot a Lot Harder," indirectly defines depression as a "natural" part of everyday life, on par with familiar women's magazines topics like bad hair days and acne. The autobiographical celebrity statements and the coverage in women's magazines present sadness, medicalized as depression, as both common and exceptional. Common because it afflicts so many people, and exceptional because it is presented as a disease that turns you into a sick subject.

The self-identified sad girls active on sites like Tumblr are crystallizations of the sad structure of feeling seen in the larger popular culture. They write about their psychiatric diagnoses and the experiences that come with them, like wanting to stay in bed all day and being under the treatment of a therapist. But importantly, they do not follow a direct road-to-recovery model, whose primary goal is to get rid of the negative feelings. Instead they rest in the sadness without immediately fleeing it. The sad girls may identify as sick subjects, but the sickness is conceptualized in multifaceted ways that refuse traditional biomedical strategies that aim to instantly cure.

\section{Delineating an archive}

Tumblr has established a reputation among the major social media sites as "a comfortable place to be honest, weird, and maybe even depressed" (Premack 2016). It differs from other social media platforms in a few significant ways: it 
functions more like a blog than other social media sites, the content posted is published to each user's own Tumblr page which is visible also to non-users (the design of this page can be endlessly modified, something I elaborate on below). The social aspects of Tumblr resemble other platforms in a few ways: users follow each other via linear news feeds like that on Facebook, Instagram, or Twitter; one can post original content in the form of text, image, quote, link, chat, audio, and video; and one can reblog or like someone else's posts. Much of the content that circulates among the sad girls has been reblogged thousands of times. ${ }^{1}$ This number is trackable in a "notes"-section found at the bottom of each post, each note representing one reblog or like. Study of the phenomenon of the sad girl on Tumblr cannot include only an examination of a few users' original content, but needs to follow the content that is being spread in a meme-like fashion on the site.

The sad girl affect can be said to circulate in this meme-like way, utilizing the distributing and repetitive capacity of the meme. Jack Bratich has studied the memes generated around and out of the Occupy Wall Street (OWS) movement to gain "insight into its mediated subjective processes" (2013 p. 2). He explains that "OWS started as a meme by meme specialists and then mutated into a meme-generator, flashmob, and platform” (2013 p. 3). Bratich defines OWS as a potential aggregator of subjectivities, arguing that the movement "could be a name for an aggregate of operations, even an emergent subjective figure" (2013 p. 3). I think it can be helpful to think of the figure of the sad girl as constituting a similar "mediated subjective process." Through the sharing and reblogging of affective images the subject position of the sad girl emerges and becomes available for users to inhabit.

The archive I draw on here is not a fixed or limited set of Tumblr accounts, but rather content I have seen circulated multiple times among the sad girls I follow on the site. I have paid particular attention to the posts with a high number of notes, or reblogs. Importantly, the sad girl affect is not contained only on Tumblr, but can be seen on sites like Instagram and Pinterest as well. Due to its technological affordances like pseudonyms and modifiable HTML (Renninger 2014), Tumblr lends itself to a sad girl aesthetic. The majority of these users do not use their real names, as is common practice on Facebook and Twitter. This allows for a more open sharing of personal experiences and feelings that people in their everyday lives might find alarming, "abnormal," or shameful. Several of the sad girls have also taken full advantage of the modifiable HTML, creating elaborately designed banners, including moving glitter backgrounds and gifs that reveal 
more information as you scroll over them (see http://grvnge-nicotine.tumblr.com and http://hollywood-noir.tumblr.com). For example, user Grvnge-nicotine has a header that shows a picture of Uma Thurman in Pulp Fiction smoking a cigarette, displayed on a background of crystals and pink pills. Surrounding, and on top of, this image are phrases like "I hate everything," "anti-you," and "you little shit" in various figurations and colors. In the top left corner of her site is a spinning pack of Marlboro cigarettes, which, if you hover over it, reveals informational blurbs under the headings "About me," "Quote of the moment," "Networks," and "Featured in" (see Figure 4).

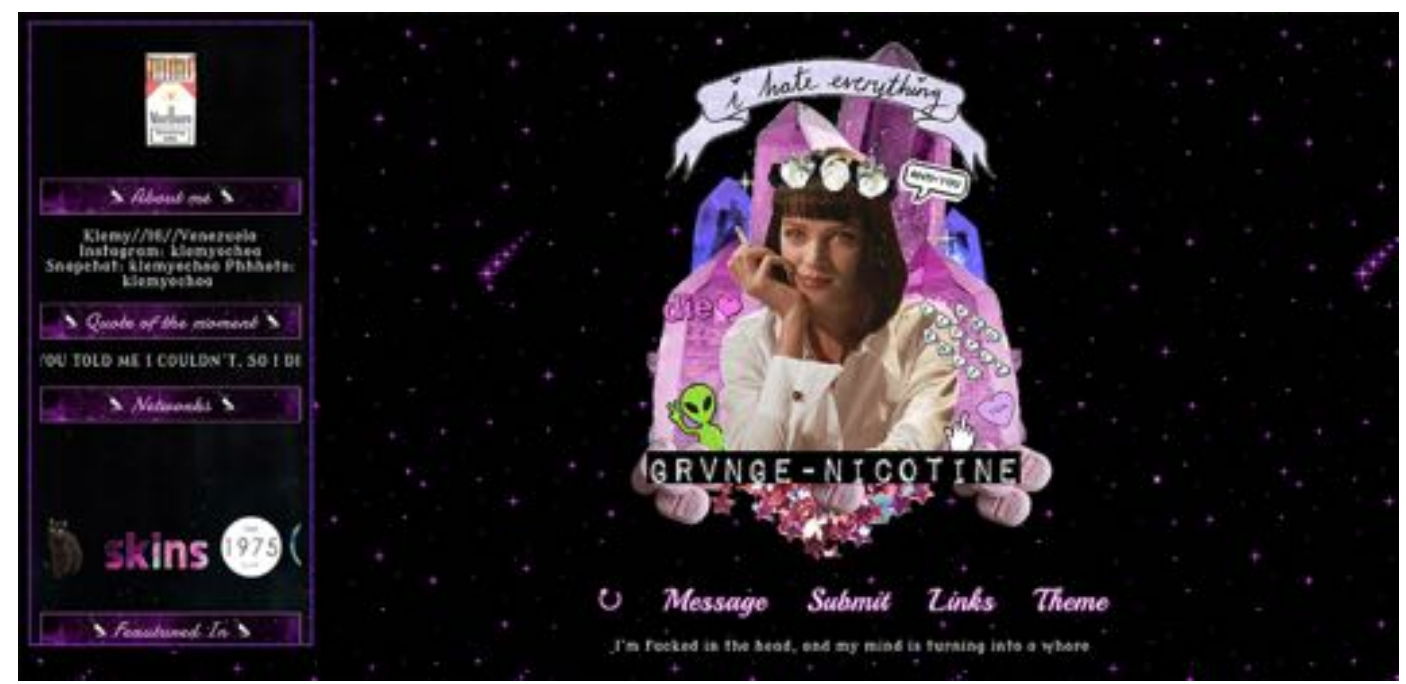

Figure 4: Grvnge-nicotine, 2017

When one scrolls down the page, the posts made by grvnge-nicotine are seen in chronological order, with the newest on top. This is the way most sad girls design their Tumblr blogs, and it shows their posts lined up together in about five columns, creating a larger compositional image that conveys a shared sad girl aesthetic (see Figure 5).

But, as Bryce Renninger points out in his study of counterpublics on Tumblr, "with changes in platforms and networks of users, media ideologies shift" (2014 p. 5). Such shifts contribute to the move from one platform to another, or the "spreading out" of activity across multiple platforms. The sad girl phenomenon can thus not be defined as specific to Tumblr. The "mediated subjective process" 
that makes up the sad girl exists on multiple social media platforms, and consists on a continuum with the shifting representations of mental health in the mainstream popular culture mentioned above.

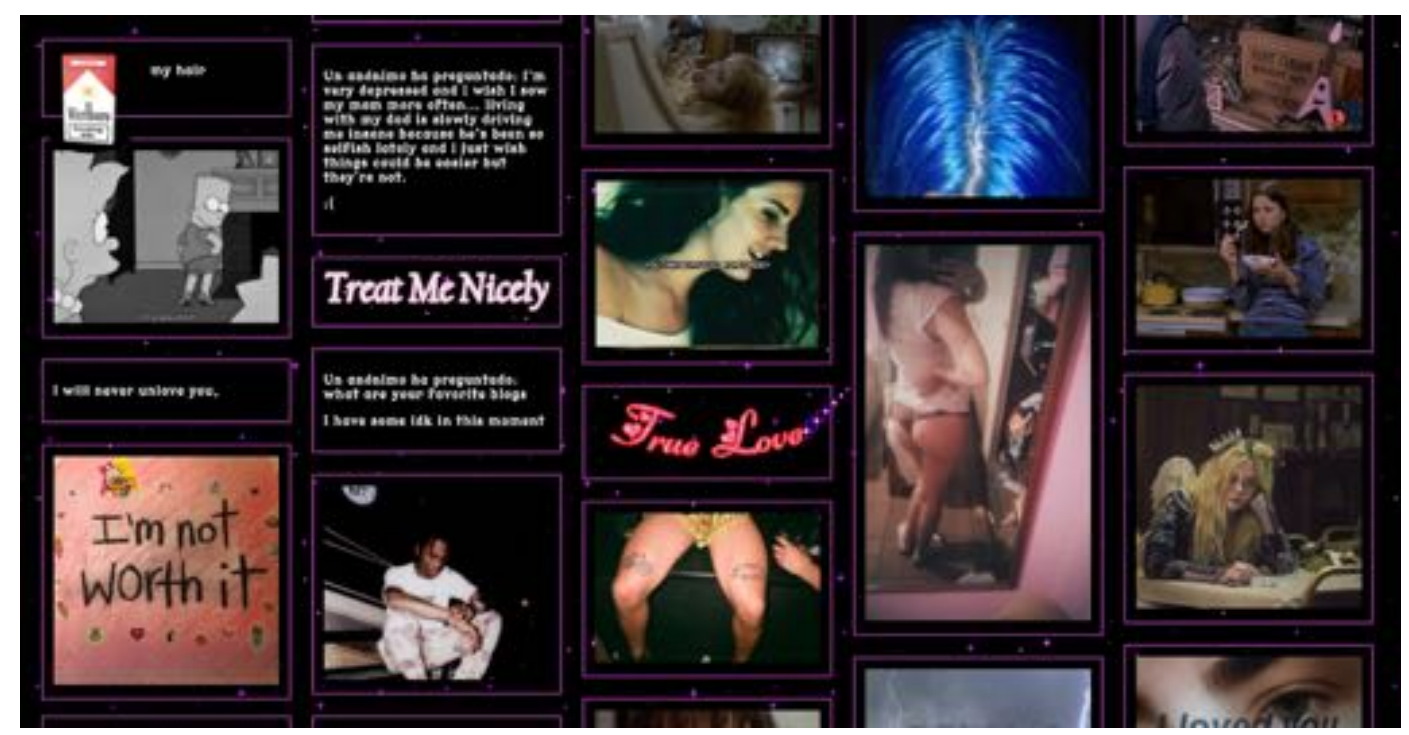

Figure 5: Grvnge-nicotine, 2017

\section{Distributed forms of perception and affective resonance}

Through the meme-like sharing of content, a shared definition of sadness is formed within the online community of sad girls. Lisa Blackman's concept of distributed forms of perception captures the way this collective voice takes shape and is expressed. She argues that: "Distributed forms of perception assume that we are always situated, speak and are spoken through by a range of others, human and non-human," specifying that these are visibly seen "in social media practices that allow traces and fragments to become linked together to assume a collective authorial voice" (2015 p. 37). The sad girls share snippets of their lives, expressed in textual or visual forms, which are then reblogged and re-circulated to users beyond the original poster's network. Blackman (2015), also theorizes distributed forms of perception in terms of Grace M. Cho's (2008) notion of a "collective psychic apparatus" (p.156). Perhaps the sad girls' emergence on social 
media can be conceptualized as a development of a collective psychic apparatus, through distributed forms of perception. The individual experiences of living with sadness/mental illness are expressed via multiple social media channels, and expressed via this medium the individuals together form a shared notion of mental health that is different than the one provided in traditional psychiatric discourse and mainstream cultural narratives. This process can also be conceptualized in terms of affective resonance, which Anna Gibbs defines as "the positive feedback loops created by affect, and in particular the tendency of someone witnessing the display of affect in another person to resonate with and experience the same affect in response" (2013 pp. 131-132). The sharing of affective content by individual Tumblr users resonates with other users, and together form a mutual "sad girl affect." Gibbs writes that "repeated experiences of affective resonance (whether "firsthand" or "mediated") produce a concatenation in which affect resonates with like-affect, so as to link otherwise unrelated scenes without producing articulable meaning" (2013 p. 133). The repetition of the sad girl affect in a recurring affective resonance creates a shared "sad girl aesthetic" whose meaning cannot be directly explained, but makes sense to the sad girls who participate in its creation and maintenance.

\section{Conceptualizations and analyses of sadness}

Are the sad girls sharing a new kind of sadness? And if so, in what ways might this challenge traditional conceptions of sadness and mental illness? Before responding to this, I will map out the background of how sadness has been portrayed in popular discourse, and how it has been analyzed.

Blackman has argued that representations of mental illness in popular discourse tend to follow a "victim to victor" narrative that constructs psychiatry as a technology of hope (2007, pp. 2, 6). In this framework, when one is afflicted with a mental health issue the first step is to acknowledge and accept the biological cause of the illness, followed by a compliance with psychiatric treatment plans, and psychotropic drugs that are hailed as necessary. The reliance on a medical diagnosis lifts "the burden of agency and responsibility" (Cvetkovich 2012, p. 88) that has historically been associated with the "crazy" label. Here, an individual's irrational behavior is not their fault, but rather caused by inevitable neurological components. The only solution to a mental health problem is to adhere to an uncritical psychiatric discourse that medicalizes the sad subject as a "patient" in need of a cure (Foucault 2006). 
This subject is by default ahistorical in that it seemingly exists in a vacuum from the surrounding culture. Socioeconomic factors like gender, race, and class are ignored in favor of biomedical explanations that hail medication and traditional psychotherapy as primary cures. This is seen in many cultural narratives where the individual who suffers tends to be white and middle class, and who, by virtue of their privilege, can represent mental illness as only rooted in neurological makeup and close family relations. An example of such a narrative is the television show You're The Worst (2014-), where one of the main characters goes through a period of clinical depression. Gretchen had suffered from depression in college, and it re-emerges seemingly out of the blue a few years later, even though her life on paper should ensure happiness. The depression is defined as clinical early on, and is portrayed as being caused by unruly brain chemicals. As we watch Gretchen struggle and subsequently get help from a therapist, we never have to worry about her health insurance (because it is set in the U.S. access to health care is a constant concern), nor about any systemic racism she may encounter in the health care system. Due to her privileges depression can be constructed as purely biomedical.

This approach simplifies what are usually complex problems with multiple causes and solutions, and ignores potential effects of cultural and socioeconomic circumstances, preventing all connections between ailments like depression and power/ knowledge structures. The blind faith in the psychiatric model also leaves those who it fails to help responsible for their own inability to heal. The individual who suffers, and for whom the medication and therapy does not work, or who would rather not take it for a variety of reasons, including bothersome side effects, assumes fault. Following the neoliberal call to self-governance, the person who remains ill despite having sought help via the traditional psychiatric channels, is made to feel that it is because she did not try hard enough, or is not compliant enough. Inadequacy in care becomes the problem of the individual rather than a call to expand the available modes of treatment. Critical analyses, on the other hand, have tended to focus mainly on the connections between power regimes and constructions of the psyche (see, for example, Rose 1998). Even though this approach takes social and cultural circumstances into account, it can result in delegitimizing feelings of sadness and depression, implying that it is only a product of power regimes and not a "real" lived experience.

I do not intend to follow either of these traditions, I wish to explore theories that examine the discourse around sadness somewhere in between the poles of proand anti-psychiatry. Like the thinkers I am most influenced by, Blackman and 
Cvetkovich, I argue a contemporary understanding of mental health must go beyond simple analyses, and instead acknowledge the complex entanglements of the prevalence of psychotropic drugs and critical thinking about them.

Cvetkovich describes how the affect-focused scholarly collective, Public Feelings, approaches depression: "a political analysis of depression might advocate revolution and regime change over pills, but in the world of Public Feelings there are no magic bullet solutions, whether medical or political, just the slow steady work of resilient survival, utopian dreaming, and other affective tools for transformation" (2012 p. 2). Can the sad girls on Tumblr constitute such a "resilient survival?" With their glorification and aestheticizing of sadness in both its artistic and medicalized iterations, the sad girls seem to fall in neither the pro- or anti-psychiatry stance. The romanticizing of sadness implies a refusal of psychiatric models that aim to cure mental illness and restore them to healthy subjects as soon as possible. The embrace of medication in a way that assigns it "coolness" and "edginess" reveals an at least partial belief in the possibility of pills to soothe symptoms and make one feel better. The sad girls, then, move in a space in between wholeheartedly accepting or completely rejecting a psychiatric model. The former because they refuse to immediately heal and choose instead to remain in their sorrow, and the latter because they acknowledge the power of psychotropic drugs to relieve symptoms. In other words, the sad girls are positioned in an ambivalent position akin to that described by the Public Feelings project.

\section{Acedia}

In her mix of memoir and scholarly study, Depression: A Public Feeling (2012), Cvetkovich examines the history of depression in Western Culture, primarily how it has been understood outside of a medical discourse that by default conceives of it as something to be immediately cured. She starts with the concept of acedia, first talked about in early Christian writings on monastic life. The term refers to spiritual crisis, inertia, carelessness, and intense feelings of disgust and disdain (Cvetkovich 2012, p. 85). Acedia has frequently been written off as too religious to be used in any understanding of depression. Rooted in spiritual thinking it is contrary to a medical model based on secular notions of progress and Enlightenment ideas. Cvetkovich, however, argues for the use of acedia in theorizing contemporary depression, as it "foregrounds matters of faith and hope 
as relevant to the experience of being stuck, which can manifest in psychic and spiritual ways, as well as biological and physical ones" (2012, p. 102). She aims to open her analysis so as to understand depression "as the product of a sick culture" (p. 102). By turning to a concept like acedia, which incorporates both the spiritual the physical, connections between culture and depression can be studied beyond the (historical) limits of secular understandings of mental health.

Cvetkovich writes that "acedia helps place the medical model of depression within the longer history of notions of not only health but embodiment of what it means to be human" (2012, p. 102). Thinking of depression as an "embodiment of what it means to be human" implies a rejection of a medical model that sees depression as something exceptional to be immediately cured away, and instead assigns it a central place in the experience of life itself. The tendency to conceive of depression as abnormal indirectly marks "feeling good" as the "normal" mood for which one should always aim. The occasional states of "feeling bad" are also accepted as normal if they do not result in the inertia and inability to act so characteristic of depression. Depression as a deviation, as an illness to be cured, fits into the neoliberal society in which we all need to be functional subjects capable of laboring. Adopting a model of acedia that places depression as central to what it means to be human, allows a move away from seeing it as exceptional. Instead, it can be viewed as something that offers an opportunity to pause and break from the requirement to constantly be a profit-making subject, and provide a chance to process the emotional impacts of life under neoliberalism. In their refusal to heal, the sad girls can perhaps be an example of conceptualizing sadness as acedia.

\section{Suffering as ordinary}

Blackman writes frequently about the importance of "reframing suffering as 'ordinary'” (2015 p. 26; see also Blackman 2001; Blackman \& Walkerdine 2001), which follows the trajectory of repositioning negative affects at the center rather than the periphery of human life. She explains that conceiving "suffering as 'ordinary'" reframes it as "not an exceptional phenomenon, but rather part and parcel of the costs of neo-liberalism(s)" (2015 p. 26). By conceptualizing suffering as ordinary, one can, Blackman argues, acknowledge the "difficulties of living normalised fictions and fantasies of femininity that [are] produced within [neoliberalism(s)] ... as signs of personal failure, inadequacy and the associated economies of pain, fear, anxiety and distress that keep these apparatuses alive and 
in place" (2015 p. 26). Seeing suffering as ordinary, and not something that can immediately be cured or done away with, makes it possible to connect suffering with the neoliberal power structures that control our wellbeing while telling us that we have endless possibilities to maximize our mental and physical health. The sad girls do seem to see suffering as ordinary, as they rest in it as a part of everyday life that they cannot get away from. For example, a post by user straightboyfriend that has been reblogged and liked 42,304 times reads "its summer vacation you know what that means! Isolation \& severe depression” (straightboyfriend 2016). Another post, by user gothicprep, which has been reblogged and liked 58,058 times, reads "how do i contour my abandonment issues?" (gothicprep 2016). Both posts imply a base level of constant sadness, and the ironic tone serves to establish shared connections with other users who have had similar experiences. The connection of sad feelings (isolation, severe depression, and abandonment issues) with usually joyful and "normal" things (summer vacation and makeup) turns the negative feelings into a shared comedic discourse.

\section{Melancholia}

Besides accepting sadness as ordinary, the sad girls also display an idealization of sadness. This could be described by the concept of melancholia, which has also been used as an alternative to contemporary medical models. Cvetkovich explains that melancholia allows for "a return to a time when sadness could be viewed in other ways, including as a normative part of cultural experience, and even, most notably in the case of Renaissance and Romantic understandings that have had a persistent influence, as a creative force" (2012 p. 107). It is something that touches more upon sadness in general, a sadness that is creative and inspiring, rather than the debilitating "stuck-ness" associated with depression.

There is also an element of pleasure in melancholia. Freudian psychoanalysis defines the melancholic as "one who incorporates a lost object of desire into her ego, so that she never fully experiences the loss, since the loved one, even in absence, becomes merged with the self" (Berlant 2012, p. 29). The lost love becomes integral to the make-up of the subject, to her entire self-image, and the incorporation of the loss takes the form of masochistic pleasure in love relationships. The pleasurable and creative aspect of melancholia differs significantly from the 
spiritual crisis and inertia of acedia. I think one can hold on to both concepts as ways of thinking through depression and sadness. In relation to the sad girls, melancholia can capture the pleasure they derive in glorifying sadness, and acedia the inertia that co-exists with this romanticizing.

Melancholia might be said to glorify feeling bad because of its promise to produce great art; it is the driving force of the archetypical tortured genius. In this way, the sad girls seem to partially adhere to a melancholic stance. There is a dedication to artists and celebrities that fulfill this role of tortured and misunderstood genius. The artist Lana del Rey is one recurring figure. del Rey is not a celebrity that has spoken out about actual struggles with mental illness, rather she has adopted a persona of being sad. She sings about female weakness and dependence in a way that makes it seem like she is enjoying it. These themes are present in much of her work, but is especially visible on her 2014 album "Ultraviolence" which is dominated by themes of submission and self-destructiveness in relation to various men. One line that particularly seems to encourage the abusive relationships portrayed throughout the album is a quote from a 1962 Carol King and Gerry Goffin song: "he hit me and it felt like a kiss," sung on the title track "Ultraviolence." The persona del Rey communicates is one that takes melancholic pleasure in not getting what she wants. The sad girls on Tumblr adopt her affect by frequently posting and reblogging images of her, sometimes with lyrics from her songs written on them. She even has a song entitled "Sad Girl" that contains the lyrics "I'm a sad girl, I'm a bad girl, I'm a bad girl." Another popular del Rey lyric that is repeatedly reblogged is "you like your girls insane," from the song "Born to Die," shared as text atop a photograph of the singer (m1nd--0ver--matter, n.d.). del Rey lends herself perfectly to the sad girl affective resonance, shown by the frequency with which images of her and her songs are reblogged and spread among these Tumblr users.

Idealizations of real life persons who inhabit the position of (female) misinterpreted and tortured genius are also common. Courtney Love, Amy Winehouse, Sky Ferreira, and celebrities who have had public breakdowns, like Britney Spears, Lindsey Lohan, and Amanda Bynes appear to reinforce a melancholic notion of sadness as romantic, mystical, and inspirational (see Got-you-where-i-want-you, 2017, infinitystorms, and cling2something, 2017). Acedia and melancholia are ways of conceptualizing sadness beyond the pro- or anti- medical model offered by psychiatry. I believe these concepts can explain the activity of the sad girls by providing ways of thinking about the simultaneous resting in, and normalizing of, sadness and the glorification of feeling bad. 


\section{Possibilities of sadness}

Blackman and Cvetkovich have written about the "productive possibilities of negative states of being," which seek to "to de-pathologise shame, melancholy, failure, depression, anxieties and other forms of 'feeling bad,' to open up new ways of thinking about agency, change and transformation" (Blackman 2015, p. 25). Cvetkovich describes how the Public Feelings project uses the term impasse to refer to "a state of both stuckness and potential" (2012, p. 21). She explains that the notion of impasse maintains "a hopefulness about the possibility that slowing down or not moving forward might not be a sign of failure and might instead be worth exploring" (p. 21). Impasse could be one kind of productive possibility, allowing sufferers to rest in "bad" feelings without having to immediately work to get rid of them. Similar to Blackman's notion of suffering as ordinary (2015), the concept of impasse allows us to think about and process the power structures that inevitably affect the possibilities of succeeding at a healthy life. Among the sad girls noted, there is not an overt political engagement that directly connects suffering to structures of power. But the mere act of resting in sadness, as they do, might function as an impasse, where the refusal to move forward becomes a protest of the neoliberal demands of becoming a laboring and "happy" subject.

\section{A supportive community?}

It is in the collective notions of sadness that develop among the sad girls, that the alternative conceptualizations of sadness move from theoretical to actual. By sharing their own views of sadness on the multimedia platform, it becomes possible for Tumblr sad girls to explore their feelings together, and potentially provide support for one another by validating each other's experiences. The glorification of sadness found among the sad girls sometimes borders on encouragement of self-destructive behavior. But, paradoxically, the fact that these experiences are shared within the virtual space of Tumblr intervenes in the glorified isolation and presents the possibility of a supportive collective. In the middle of Lana del Rey quotes and pictures of pills, more "positive" posts are found. For example, a gif of moving text that reads "sext: I want to be good for your mental health" (hollywood-noir, 2015b). "Sext" refers to the communication of sexual acts via text message, or, the text version of phone sex. "Sext:" followed by various sentences is a meme that juxtaposes the sexual connotations of "sexting" with non-sexual 
phrases for comedic effect. Saying "I want to be good for your mental health" in this context communicates a tender longing for emotional support and stability.

Anne Allison recounts an experience during fieldwork in Japan where she attended a talking event that aimed to prevent the contemporary suicide trend. She explains that the aim of the event was "to share stories of near-death experiences as a means of assisting each other ... in trying to stay alive" (2013 p. 130). The participants told their stories of depression, loneliness and withdrawal, including how they managed to move beyond the worst point of despair and avoid suicide. The turning point for many was precisely the moment when they learned that they were not alone in feeling sadness and despair. Emily Martin describes a similar phenomenon occurring in the support groups she visited for her study of bipolar disorder in American culture (2009). Here the participants formed a collective understanding of what it means to live with the diagnosis based on their own and each other's personal experiences of navigating a flawed psychiatric system.

Through distributed forms of perception and meme-like spreading of multiple voices, the phenomenon of the sad girl can be said to manifest an alternative collective psyche (as discussed by Blackman 2015 and Cho 2008). By forming a discourse where multiple voices and experiences of living with mental illness get to be heard, an alternative and multifaceted way of conceptualizing sadness becomes available. This gives sufferers access to a potentially supportive collective of other sufferers. Here, those who fail to be helped by traditional psychiatric discourse can get a chance to be heard, learn that they are not alone, and possibly receive non-medicalized modes of support.

\section{Endnotes}

1. When you reblog a post on Tumblr you repost the original content (text, visuals, or audio) to your followers and on your personal Tumblr blog. You can choose to include previous comments or leave them out. The username of the person you reblog from is always included in the new post, as is the original poster, who is referred to as "source" at the bottom of the post. 


\section{References}

Allison, A. (2013). Precarious Japan. Durham and London: Duke University Press. AnimatedText. (2016). having a threesome with anxiety and depression. [Blog] Tumblr.com. Available at: from http://animatedtextgifs.com/ post/142548878872/requested-by-0n-your-knees [Accessed: October 21, 2017].

Berlant, L. (2012). Desire/Love. Brooklyn, NY: Punctum Books.

Blackman, L. (2015). Affective politics, debility and hearing voices: Towards a feminist politics of ordinary suffering. Feminist Review, 111 (1), pp. 25-41.

Blackman, L. (2001). Hearing Voices: Embodiment and Experience. London and New York: Free Association Books.

Blackman, L. (2007). Psychiatric culture and bodies of resistance. Body E Society, 13 (2), pp. 1-23.

Blackman, L., \& Walkerdine, V. (2001). Mass hysteria: Critical Psychology and Media Studies. Hampshire, UK \& New York: Palgrave Macmillan.

Bratich, J. (2013). Occupy All the Dispositifs: Memes, Media Ecologies, and Emergent Bodies Politic. Communication and Critical/Cultural Studies, 11 (1), pp. 64-73.

Cho, G. M. (2008). Haunting the Korean diaspora: Shame, secrecy, and the forgotten wars. Minneapolis and London: University of Minnesota Press.

cling2something. (2017). Amy Winehouse. [Blog] Tumblr.com. Available at: http:// cling2something.tumblr.com/post/163766968492158824899040 [Accessed: October 21, 2017].

Cvetkovich, A. (2012). Depression: A Public Feeling. Durham and London: Duke University Press.

Foucault, M. (2006). History of Madness (Vol. 1). Oxon, UK: Routledge.

Gevinson, T. (2014, April 30). Not a Girl, Not Yet a Woman: The Two Sides of Miley Cyrus. Elle.com. Available at: http://www.elle.com/culture/celebrities/a12/miley-cyrus-may-cover-story. [ Accessed: October 21, 2017].

Gibbs, A. (2013). Apparently unrelated: Affective resonance, Concatenation and Traumatic Circuitry in the Terrain of the Everyday. In M. Atkinson \& M. Richardson (Eds.), Traumatic Affect. Cambridge, U.K.: Cambridge Scholars Publishing, pp. 129-147. 
Got-you-where-i-want-you. (2017). Courtney Love. [Blog] Tumblr.com. Available at: http://got-you-where-i-want-you.tumblr.com/post/158824899040 [Accessed: October 21, 2017].

Gothicprep. (2016). how do i contour my abandonment issues? [Blog] Tumblr.com. Available at: http://gothicprep.tumblr.com/post/139090742155/ how-do-i-contour-my-abandonment-issues [Accessed: October 21, 2017].

Grvnge-nicotine. (2015). Medicated. [Blog] Tumblr.com. Available at: http:// grvnge -nicotine.tumblr.com/post/115523875193/satannnfuckedme0ver-wastedlilacs-soft [Accessed: October 21, 2017].

Havic-dp. (2014). S 90 3. [Blog] Tumblr.com. Available at: http://havic-dp.tumblr. com/post/90219378205 [Accessed: October 21, 2017].

Hollywood-noir. (2015a). Lisa Simpson. [Blog] Tumblr.com. Available at: http:// hollywood-noir.tumblr.com/post/116832925747/soft-grunge/amp [Accessed: October 21, 2017].

Hollywood-noir. (2015b). sext: I want to be good for your mental health. [Blog] Tumblr.com. Available at: http://hollywood-noir.tumblr.com/ post/125186281077/flowers-in-my-hair-demons-in-my-head [Accessed: October 21, 2017].

Infinitystorms. (n.d.). Sky Ferreira. [Blog] Tumblr.com. Available at: http://infinitystorms.tumblr.com/post/93182653915 [Accessed: October 21, 2017].

Kliegman, J. (2015, December 18). 2015: The Year Mental Illness Finally Got Some Respect on

TV. Vulture.com. Available at: http://www.vulture.com/2015/12/mental-illnessgot-some-respect-on-tv-in-2015.html [Accessed: October 21, 2017].

Less-love-more-alcohol. (n.d.). 100\% Sad. [Blog] Tumblr.com. Available at: http:// less-love-more-alcohol.tumblr.com/post/158888514189/successfulling [Accessed: October 21, 2017].

m1nd--0ver--matter. (n.d.). you like your girls insane. [Blog] Tumblr.com. Available at: http://m1nd--0ver--matter.tumblr.com/post/120501681047 [Accessed: October 21, 2017].

Martin, E. (2009). Bipolar Expeditions: Mania and Depression in American Culture. Princeton: Princeton University Press.

McCall, R. (2017, February 17). 7 Times Selena Gomez Spoke Up About Mental Health. Health.com. Available at: http://www.health.com/anxiety/selena-gomez-anxiety-depression-quotes [Accessed: October 21, 2017] 
Premack, R. (2016, October 24). Tumblr's Depression Connection. TheRinger. com. Available at: https://theringer.com/tumblr-communities-depression-mental-illness-anxiety-c2ca927cd305 [Accessed: October 21, 2017]

Pugachevsky, J. (2014, November 7). 27 Celebrities On Dealing With Depression And Bipolar Disorder. BuzzFeed. Available at: https://www.buzzfeed.com/ juliapugachevsky/celebrities-on-dealing-with-depression-and-bipolar-disord [Accessed: October 21, 2017]

Renninger, B. J. (2015). "Where I can be myself... where I can speak my mind": Networked Counterpublics in a Polymedia Environment. New Media \& Society, 17 (9), pp. 1513-1529.

Rose, N. (1998). Inventing our Selves: Psychology, Power, and Personhood (Cambridge Studies in the History of Psychology). Cambridge, UK: Cambridge University Press.

Shah, B. (2016, September 14). Why Selena Gomez Talking About Her Depression and Anxiety Helps Everyone. Elle.com. Available at: http://www.elle. com/culture/celebrities/a39233/selena-gomez-anxiety-depression/ [Accessed: October 21, 2017].

Showalter, E. (1985). The Female Malady: Women, Madness, and English culture, 1830-1980. New York: Pantheon Books.

Stinson, A. (2017, May 12). Depression Makes Looking Hot a Lot Harder. Marieclaire.com. Available at: http://www.marieclaire.com/culture/news/a27106/ depression-symptoms-hygiene [Accessed: October 21, 2017].

Straightboyfriend. (2016). its summer vacation you know what that means! [Blog] Tumblr.com. Available at: http://straightboyfriend.tumblr.com/ post/145484278234/its-summer-vacation-you-know-what-that-means [Accessed: October 21, 2017]

Sweet-despondency. (2016). I told my therapist about you. [Blog] Tumblr.com. Available at: http://sweet-despondency.tumblr.com/post/148574795828 [Accessed: October 21, 2017]

Vogue.com. (2017, March 16). Selena Gomez Gets Real About Anxiety-And How Therapy Changed Everything. Vogue.com. Available at: https://www. vogue.com/article/selena-gomez-rehab-therapy-mental-health-depression 